\section{Anomaly in the transitional arrangements for the Mental Health Act 2007}

The new Mental Health Act 2007 (Department of Health, 2008) takes New Ways of Working (Royal College of Psychiatrists \& National Institute for Mental Health in England, 2005) to a new level. For the first time in history, nurses, psychologists, social workers and occupational therapists may take on the role of responsible clinician (previously responsible medical officer), but will first have to undertake initial training and demonstrate the competencies laid out to be an approved clinician.

Transitional arrangements are in place for current responsible medical officers to become approved clinicians on 3

November 2008, when the provisions of the Act come into force, as long as they have carried out the functions as responsible medical officer in the past 12 months. Therefore, not all Section 12-approved doctors will be automatically approved as approved clinicians and therefore cannot act as responsible clinicians. This leaves trainees applying for their first consultant post and newly appointed consultants who have not acted as responsible medical officers in the past 12 months in a place of uncertainty. Provisions have not been made for these doctors who may be taking over the care of service users who may require a responsible clinician after the 3 November 2008. New appointments could be jeopardised if trusts realise potential candidates will not be able to take over as responsible clinicians after 3 November.

It is unclear whether Section 12approved doctors first have to undertake the training and demonstrate the competencies as for other professionals seeking approval as approved clinician. It is unclear how long this process would take. Interim responsible clinician arrangements have not been outlined for these doctors and it appears that trainees aspiring to become responsible clinicians have been forgotten. Clarity is urgently required.

\section{ROYAL COLLEGE OF PSYCHIATRISTS \& NATIONAL} INSTITUTE FOR MENTAL HEALTH IN ENGLAND (2005) New Ways of Working for Psychiatrists. Department of Health.

DEPARTMENT OF HEALTH (2008) Mental Health Act 2007: Consultation on Secondary Legislation. Department of Health.

*Nicole Karen Fung Specialist Registrar in Child and Adolescent Psychiatry, Brooklands, Coleshill Road, Marston Green, Birmingham B37 7HL, email: nkf@doctors.org.uk, Indra Ethirmannasingam Specialist Registrar in Child and Adolescent Psychiatry, Darwin Centre for Young People, Cambridge

doi: 10.1192/pb.32.11.437

\section{Integrity}

Bhugra (2008) says that if our trainees see us as tired, fed up and demoralised they are likely to question not only our commitment but also their own professional attributes. But there are other possibilities. Feeling tired, fed up and demoralised should lead to reflection on what internal and external factors are driving this. Our trainees should see the real world as it is and what they are signing themselves up for. It is not in their interests to see a rose-tinted picture. Questioning is good, but both they and we must ask the right questions. I see this as an issue of integrity and being honest with trainees and ourselves.

Walking in to work every day with masked depression is not healthy.

BHUGRA, D. (2008) Renewing psychiatry's contract with society. Psychiatric Bulletin, 32, 281-283.

Rafiq Memon Consultant Forensic Psychiatrist Reaside Clinic, Bristol Road South, Rednal, Birmingham B45 9BE, email: rafiq.memon@ bsmht.nhs.uk

doi: 10.1192/pb.32.11.437a

\section{An alternative to conventional care for young people with anorexia nervosa}

A community intensive therapy team (CITT) for young people with complex mental health problems was developed in South Wales in 1998 (Darwish et al, 2006). We report here a small study of 30 service users (27 female, 3 male) with anorexia nervosa, referred to CITT over a 4-year period.

Mean age at referral was 14.56 years (14.4 for females, 15.67 for males; range 12-17 years); body mass index (BMI) at referral ranged from 13.1 to 18.0 (mean= 15.52). A mean discharge BMI of 19.3 was recorded following an average period of treatment of 16.7 months for females and 10 months for males. The duration of outpatient care provided by CITT ranged from 5 months to 3.5 years for 16 patients, with the remaining 14 patients receiving ongoing intervention. During the 4-year study period no service users were admitted to hospital.

DARWISH, A., SALMON, G., AHUJA, A., et al (2006) The community intensive therapy team: development and philosophy of a new service. Clinical Child Psychology and Psychiatry, 11, 591-605.

*Anna Goel Specialist Registrar in Child and Adolescent Psychiatry, Ty Bryn Unit, St Cadoc's Hospital, Caerleon, Gwent NP18 3XQ Wales, email: anna.goel@gwent.wales.nhs.uk, Ahmed Darwish Consultant Child and Adolescent Psychiatrist, Glanrhyd Hospital, Wales

doi: 10.1192/pb.32.11.437b

\section{Limitations of observational studies with known confounders}

The recent article by Dibben et al (2008) provides positive evidence that crisis resolution and home treatment teams for older people reduce admission rates to hospital by $31 \%$. Their findings are based upon a 6-month observational study conducted before and after the introduction of the new service. We believe the results are unreliable and should be treated with caution.

The analysis of baseline characteristics shows no significant difference between the patient groups; however, it is misleading as external factors are likely to confound the results in this case.

The authors confirm that during the study period a dementia care ward was closed, as were two day-hospitals. These changes are likely to represent known confounding variables. Closure of the dementia ward will invariably lead to reduced admission rates as a direct result of reduced capacity to admit service users. The day hospital closure may also serve to raise the clinical threshold required for admission given the reduction in day attendance capacity.

No data is provided regarding in-patient bed capacity and how this was reduced following bed closures, thus readers are unable to estimate the magnitude of the potential impact upon results. In addition, no data is provided for the potential known confounding variable of out-ofarea admissions, which can occur when a hospital reaches full occupancy.

Clearly, the gold standard for study design would have been a randomised controlled trial. This is often not possible given feasibility implications. Ideally, the authors should have used a control group of service users who were not treated by the new service. This should then have been followed by appropriate use of multivariate regression analysis to account for the effects of the known confounding variables. The authors rely on past randomised research to support their findings (Johnson et al, 2005; Joy et al, 2006). The participants of the cited studies were not solely older adults and the results are therefore not directly generalisable to their sample. We accept their research is novel and designed with service limitations in mind, but we believe they offer only a basic understanding of their subject. 